\title{
Strategic Aspects of the Relation Knowledge Management - Entrepreneurial Activity of Organizations
}

\author{
Magdalena Parcheva, $\mathrm{PhD}$ \\ Technical University - Varna, Varna, Bulgaria \\ mpartcheva@tu-varna.bg
}

\begin{abstract}
The article has examined the relation between the concepts of Knowledge Management and Entrepreneurial Activity of the organization. The theoretical grounds for finding such a connection has been studied; the character of the ambiguous phenomenon of Entrepreneurial Activity of the organization has been presented. The Basic theses in the field of the Knowledge Management have been interpreted. One perspective on the strategic aspects of the relation "the Knowledge Management - Entrepreneurial Activity" has been presented. The results of the study highlight the epistemological approach as a beneficial research perspective having its genesis in the Austrian School of Economic Theory, as well as its contemporary applicability in the development of the Knowledge Management strategy and system that contribute to Entrepreneurial Activity and sustainability of competitive advantage.
\end{abstract}

Keywords: knowledge management, epistemological approach, entrepreneurial activity, entrepreneurial orientation, entrepreneurial opportunity, competitive advantage

JEL Code: M10; doi:10.36997/IJUSV-ESS/2019.8.1.94

\section{Въведение}

В условия на динамичност на средата конкурентното предимство на организацията е тясно свързано със създаването на нови, интензивни по отношение знанието продукти и технологични решения, с проявлението на проактивност към пазарните възможности, с навлизането в нови сфери на стопанска дейност. В този смисъл в теорията и практиката особена актуалност придобиват концепции като „управление на знанието“, „вътрешно предприемачество“, „предприемаческа активност на организацията““.

Предмет на изследване е връзката между управление на знанието и предприемаческа активност на организацията. Основните иели на статията се съсредоточават в направленията: (1) дискутиране на теоретичното основание на изследваната релация и представяне на същността и ролята на епистемологичния подход в теорията на предприемачеството; (2) проучване, анализ и систематизиране на резултати и основни теоретични тези в съвременните изследвания в областите „предприемаческа активност на организацията“ и „управление на знанието“; (3) представяне на една гледна точка за стратегическите аспекти на връзката „управление на знанието- предприемаческа активност на организацията“; (4) формулиране на изводи и препоръки от проведеното изследване.

\section{1. Епистемологичен подход в изследванията на предприемаческата активност: теоретични основи}

В теоретичен и методологичен план ценно знание за изучаване на феномена предприемаческа активност дава епистемологичната изследователска перспектива. Възприемането на епистемологичен подход има своето теоретично основание, произтичащо от тезите на учените от австрийската школа в икономическата теория.

През $50^{\text {те }}$ години на 20 век епистемологичният подход е възприет в концепциите на Мизес и Хайек. Според Мизес предприемаческото действие е породено от промяната в информацията, която предприемачът има за пазара. Предприемачът преценява по- добре от останалите участници на пазара бъдещите цени на продуктите; купува фактори за производство, произвежда продукта на по- ниски общи разходи в сравнение с приходите, които ще получи от продажба на готовия продукт, а предприемачеството е движеща сила на пазарната система. В своите изследвания Хайек развива тезата за разделение на знанието и 
откроява явно знание и неявно знание. Явното знание се притежава съзнателно и може да се разпространява и съхранява от формалните институции. Неявното знание не се придобива преднамерено, не се предава, отчуждава и прехвърля и е свързано с неформалните институции. Хайек разглежда пазарьт като спонтанен ред, а конкуренцията като процедура на откриване (Коева, 2002).

Позовавайки се на тезите на Мизес и Хайек и прилагайки епистемологичния подход, Киринер разработва концепцията за „предприемаческото откриване“, превърнала се в емблема на австрийската школа в икономическата теория. Основни елементи в концепцията на учения са ролята на знанието и на откриването на възможности в процеса на постигане на пазарно равновесие. Кирцнер разглежда постигането на равновесие на пазара като процес, чиято основна движеща сила е предприемаческото откриване. Във връзка със същността на понятието „предприемаческо откриване“ Киринер (1997) пише: „предприемаческото откриване представлява постепенно, систематично избутване на границите на игнориране на непознатото като по този начин се увеличава взаимната информираност между участниците на пазара по отношение на цени, количество, качество, стойности, при които се постига пазарно равновесие“.

Концепцията за предприемаческите възможности е епистемологична по своя характер. Анализирайки тезите на Кирцнер, можем да откроим някои специфики на предприемаческата възможност:

Предприемаческата възможност адресира неразпозната и реално постижима възможност за печалба на предприемача.

- $\quad$ Предприемаческите възможности са свързани с осведомеността на участниците на пазара.

- Предприемаческите възможности не могат да бъдат разпознати единствено чрез систематично и планирано тьрсене на информация. По същество предприемаческата възможност е скрита и неявна; предприемаческата възможност е свързана с неявното знание.

Откриването на предприемачески възможности е свързано с будността на предприемача, както и с изненадата, с неочакваността, които също са свързани със субективното възприятие от страна на предприемача.

Откриването на пазарни възможности не следва да се разглежда единствено като процес на разпознаване на вече съществуващи пазарни несъвършенства. Новата пазарна възможност предполага поглед в бъдещето, а улавянето на пазарната възможност е пречупено през субективния свят на предприемача.

Оползотворяването на предприемаческа възможност може да предполага дейност, която не е високо иновативна по своя характер. От друга страна Киринер не изключва, че новата пазарна възможност може да е тясно свързана с иновативна комбинация от ресурси, която позволява готовия продукт да се продаде на цена, надвишаваща разходите за производство.

Ключово значение в теорията за предприемаческо откриване на Кирцинер има будността на предприемача. Същността на предприемаческата будност е свързана със знанието, но не със знанието за „наблюдаемите феномени на пазара“ като цени, на които стоките се разменят, количество, цени на факторите за производство, производствени методи и др. С понятието „будност“ се обозначава специфичен вид знание на предприемача, а именно знание, къде да се търсят подходящите информация и знание, необходими за вземане на решение за предприемане на стъпки към непознатото, неизвестното, към оползотворяване на предприемаческа възможност.

В изследването „Иновации и предприемачество“, базирано на епистемологичния подход са формулирани седем източника на благоприятни възможности за иновации и предприемачество: неочакваното, несъответствията, нужда на процеса, браншови промени, ново знание, демографски промени, промени в ценностите и възприятията (Дракър, 2002). 
Тази систематизация на източниците на предприемачески възможности позволява насочване на будността на предприемача в определени направления и по този начин създава предпоставки и насьрчава процеса на предприемаческо откриване. Ученият развива тезата за системното предприемачество и необходимостта от целенасочено тьрсене на промени и анализ на възможностите, които те разкриват за иновации (икономически или социални). Иновацията се разглежда като специфичен инструмент на предприемачите, чрез който те оползотворяват нови възможности. Предприемаческите възможности са фокус в редица проучвания с предмет различни аспекти на предприемаческия процес и предприемаческото управление (Коев, 2006, Di Muro, 2018)

В съвременните изследвания по предприемачество епистемологичният подход очертава плодотворна изследователска перспектива за проучвания с различен предмет, а именно:

- Предприемаческа активност и икономическо развитие.

- Предприемаческа активност и регионална икономика.

- Предприемаческа култура.

- $\quad$ Епистемологични специфики на процеса на създаване на нов бизнес.

- $\quad$ Епистемология - социално предприемачество.

- Епистемологичен подход за изследване на различни аспекти на предприемаческото управление на утвърдената организация.

Приложението на епистемологичния подход за проучване на предприемаческото управление на утвърдената организация се разглежда във връзка с концепцията „управление на знанието“ и с връзката между знание и предприемаческа активност на организацията.

\section{2. Предприемаческа активност на организацията}

Предприемаческата активност на организацията е нееднозначно разбиран и изследван от различна гледна точка феномен. Анализът на теоретичните и емпиричните проучвания по проблематиката позволява да откроим различни форми на проявление на предприемаческа активност на организацията, всяка от които притежава своя специфика.

В унисон с концепцията на Pinchot (1985) предприемаческата активност описва съвкупността от дейности в големите компании, които са насочени към генериране на нови идеи и създаване на иновации. Според тази гледна точка предприемаческите дейности се осъществяват от специалистите или от група специалисти. Те се стимулират от страна на висшето ръководство на предприятието и се „вдъхновяват” от т.нар „вътрешен предприемач": човекът, който поема отговорността да превърне идеята за нов продукт в печеливш бизнес за компанията. В този смисъл вътрешното предприемачество представлява система, която ускорява и прави възможно създаването на иновации в големите предприятия посредством мобилизиране на предприемаческия талант на вътрешните предприемачи. Задържането на тези кадри и реализирането на техните идеи допринася за преврьщането на компанията в най- добрия иноватор.

Според концептуалния модел на Guth и Ginsberg (1990) предприемаческата активност на организацията представлява съвкупност от дейности по създаване на бизнес венчър и обновяване на организацията. В него авторите се позовават на гледната точка на Шумпетер за предприемачеството и пишат: "новите комбинации от ресурси трансформират организацията в нещо изцяло ново, съвсем различно от това, което тя е била преди. Тази промяна на организацията от нещо старо в изцяло ново е отражение на предприемаческото поведение". Корпоративното предприемачество включва два вида процеси:

(1) създаване на нов бизнес венчър в рамките на съществуваща организация;

(2) стратегическо обновяване на компанията и промяна на ключови бизнес процеси.

Съвременно изследователско направление проучва предприемаческата активност като специфичен вид поведение на организацията. Разглеждането на предприемаческата 
активност като специфичен вид поведение на компанията се базира на тезите на Miller (1983) и Covin и Slevin (1991), които в последствие са доразвити от други учени.

Според Miller (1983) поведението на организацията може да се разглежда в рамките на диапазона „непредприемаческо поведение - предприемаческо поведение”. Организациите с предприемаческо поведение се ангажират в създаване на иновации, предприемат рискови начинания, проявяват проактивност като първи извеждат на пазара иновации, с което предизвикват конкурентите.

Covin и Slevin (1991) изследват предприемаческата активност като поведение на организацията, което се отличава с иновативност, риск и проактивност. Учените застъпват тезата, че предприемачеството може да се разглежда като направление на стратегическата позиция и разработват и валидират модел, който откроява движещите сили и последствията от предприемаческата позиция, както и факторите, които влияят на връзката между предприемаческа позиция и успех от стопанската дейност. Друго направление на проучване разглежда предприемаческата активност като свързана с „процесите, практиките и дейностите по вземане на решение, които водят до нов бизнес“ (Lumkin, Dess, 1996; Covin, Wales, 2019).

Възприемането на тази изследователска перспектива предполага фокус върху вписването на принципите на предприемачеството в управлението. Като антипод на йерархичното управление предприемаческото управление предполага интегриране на предприемаческия начин на мислене в стратегиите, организационната структура, организационната култура, политиките по управление на човешките ресурси, приложение на специфична политика по отношение на ресурсите, разработване на метрики за измерване на поведението на организацията; оценка на средата от позициите на предприемачеството и търсене на възможности за насърчаване на предприемаческата активност с оглед постигане на устойчиво конкурентно предимство.

В стратегически план основен фокус на предприемаческата активност на утвърдената организация е постигането на конкурентно предимство чрез иновативните решения и новите бизнес венчъри, създадени от компаниите.

\section{3. Знанието- стратегически фактор в съвременната организация}

В теорията и практиката на стратегическото управление знанието се разглежда като фактор, който допринася за устойчивост на конкурентното предимство. От гледна точка на стопанската организация същността на понятието „знание“ се изразява в следните направления:

Знанието пряко свързано със субекта- специалистите и ръководителите в организацията- с тяхната експертиза, осведоменост, опит, ценности, възприятия, преценка.

Знанието се прилага съзнателно и несъзнателно от специалиста при решаване на задачи и проблеми.

По своя характер знанието в организацията е явно и скрито. Явното знание е отразено в документите, процедурите, в споделената за всички и/или според нивото на достъп информация. Скритото знание може трудно да бъде изразено, то се притежава от всеки специалист. Скритото знание е въплътено в организационната култура- в организационните ценности, норми, ритуали.

Знанието в организацията е индивидуално и колективно. Индивидуалното знание е създадено от индивида и е негово лично знание. Колективното знание е създадено от групата или от организацията и е резултат от колективните действия. Знанието на отделния специалист се превръща в знание на организацията в резултат динамичното взаимодействие между скрито и явно знание, осъществявано посредством процесите на социализация, отчуждаване, комбиниране и усвояване (Nonaka, 1994).

Предмет на управлението на знанието е прилагането на систематичен подход по 
отношение фактора знание в организацията. По своята същност управлението на знанието е интердисциплинарна област, заимствала и доразвила тези и теоретични постановки от информационния мениджмънт, управлението на човешките ресурси, организационната теория, информационните технологии.

Анализът на различни изследвания и теоретични постановки (Alavi, Leidner, 1999, Dalkir, 2005; Martins et.al., 2019) позволява да се откроят следните специфики на управлението на знанието, разкриващи същността и направленията на изследване на концепцията в стратегически план:

Управлението на знанието се фокусира върху свързаните със знанието процеси: привличане, създаване, обмен, съхраняване, приложение на знание и организационно учене.

Управлението на знанието се фокусира върху интелектуалния капитал и върху връзката между интелектуалните активи (явни и неявни) и резултатите от стопанската дейност.

- $\quad$ Фокус на управлението на знанието е взаимодействието между скрито и явно знание в организацията.

Систематичното управление на знанието обхваща всички управленски равнища: стратегическо, тактическо и оперативно ниво.

Концепцията предполага създаването на система за управление на знанието като информационна система, която интегрира хора и технологии и обезпечава специфични процеси, свързани със знанието.

Организационното учене е ключов процес в рамките на концепцията „управление на знанието“ с предмет усъвършенстване и развитие на знанието и компетентностите на организацията.

Управлението на знанието е тясно свързано със спецификите на организационната култура като трансмитер на скрито знание в организацията.

Приложението на управление на знанието се свързва с предимства като повторно използване на най- добрите практики; скъсено време за изпълнение на работните задачи и процеси; редуциране на разходите за прехвърляне от проект на проект; концентриране върху интелектуалния капитал.

Емпирични проучвания свидетелстват за връзката между управление на знанието и иновации (Leiponen, 2006; Inkinen, Kianto, Vanhala, 2015).

Управлението на знанието цели получаване на конкурентно предимство в резултат специфичното знание и опит в организацията.

\section{4. Управление на знанието и предприемаческа активност на организацията: стратегически аспекти и области на релация}

Управлението на знанието и предприемаческата активност на организацията са две отделни концепции, всяка от които има собствен предмет и специфики.

Приложението на двете управленски теории допринася по различен начин за стратегическото развитие на организацията и за постигане на конкурентно предимство. Въпреки различията, същността на предприемачеството и епистемологичния подход за изследване на предприемаческата активност, дават теоретично основание за търсене на релация между двете концепции. В свое изследване Pinchot, G. и Pinchot, E. (1996) представят концепцията „интелигентна организация“, в която управлението е основано на знанието и принципите на предприемачеството. Michael, Storey и Thomas (2002) извеждат мениджмънта на знанието като една от основните теми в предприемаческото управление. Фокус на редица съвременни проучвания са отделни аспекти на връзката между знание и предприемаческо поведение на организацията като: организационно учене- компетентностивътрешно предприемачество (Antoncic, Hisrich, 2003); свързани със знанието процеси изпълнение на различни стратегии за корпоративно предприемачество (Kazanjan, Drazin, 
Glynn, 2002); създаване на знание- проучване на пазара- иновации - предприемаческо поведение на организацията (Alshanty, Emeagwali, 2019). Това свидетелства за актуалността и значимостта на проблематиката. Проследявайки теоретични и емпирични студии в областта, можем да направим извода, че не са многобройни систематичните изследвания, обхващащи ключови компоненти, които са общи за концепциите управление на знанието и предприемаческа активност на организацията.

В статията застъпваме тезата, че извеждането на стратегически аспекти на релация между двете концепции, следва да се основава на оценка на мястото, ролята, подходите, моделите и практиките, присъщи за всяка една от тях.

Анализът на различни теоретични постановки позволява да направим следното сравнение между управление на знанието и предприемаческа активност (табл.1).

Таблица 1 Управление на знанието и предприемаческа активност: стратегически аспекти

\begin{tabular}{|c|c|c|}
\hline Компонент & Управление на знанието & $\begin{array}{c}\text { Предприемаческа активност } \\
\text { на организацията }\end{array}$ \\
\hline Основен фокус & $\begin{array}{l}\text { • Свързани със знанието } \\
\text { процеси } \\
\text { - Интелектуален капитал } \\
\text { • Взаимодействие между } \\
\text { скрито и явно знание } \\
\text { - Връзка „знание- устойчиво } \\
\text { конкурентно предимство“ }\end{array}$ & $\begin{array}{l}\text { - Създаване на нов бизнес от } \\
\text { страна на утвърдена компания } \\
\text { • Стратегическо обновление } \\
\text { - Вписване на принципите на } \\
\text { предприемачеството в } \\
\text { управлението } \\
\text { • Връзка „иновации/ нов } \\
\text { бизнес- устойчиво } \\
\text { конкурентно предимство“ }\end{array}$ \\
\hline Стратегии & $\begin{array}{l}\text { - Стратегия по отношение на } \\
\text { знанието: подходи на кодиране } \\
\text { и персонализация } \\
\text { • Стратегически анализ на } \\
\text { процедурите, методите и } \\
\text { информационните системи } \\
\text { • Определяне на } \\
\text { стратегически важното знание } \\
\text { за организацията } \\
\text { • Връзка „знание- } \\
\text { стратегически цели“ }\end{array}$ & $\begin{array}{l}\text { • Ориентация към } \\
\text { благоприятните възможности } \\
\text { за иновации и } \\
\text { предприемачество, тяхната } \\
\text { оценка и оползотворяване } \\
\text { • Предприемачески } \\
\text { стратегии } \\
\text { • Стратегически анализ на } \\
\text { потенциала на организацията } \\
\text { по отношение на } \\
\text { предприемачеството }\end{array}$ \\
\hline $\begin{array}{c}\text { Организационни } \\
\text { форми }\end{array}$ & $\begin{array}{l}\text { • „Обърнати“ форми- } \\
\text { организация спрямо фактора } \\
\text { „знание“ } \\
\text { • Мрежови организационни } \\
\text { форми }\end{array}$ & $\begin{array}{l}\text { • Мрежови организационни } \\
\text { форми } \\
\text { • Формиране и } \\
\text { функциониране на } \\
\text { самоорганизиращи се екипи, } \\
\text { на които е осигурена свобода } \\
\text { да разработват и реализират } \\
\text { предприемачески проекти }\end{array}$ \\
\hline Процеси & $\begin{array}{l}\text { - } \text { Създаване на знание } \\
\text { - } \text { Обмен на знание } \\
\text { - } \text { Съхраняване на знание } \\
\text { - } \text { Организационно учене }\end{array}$ & $\begin{array}{l}\text { • Благоприятна възможност } \\
\text { за предприемачество- } \\
\text { предприемаческа идея } \\
\text { • П Предпроектно проучване- }\end{array}$ \\
\hline
\end{tabular}




\begin{tabular}{|c|c|c|}
\hline & & $\begin{array}{l}\text { бизнес модел } \\
\text { • Бизнес модел- привличане } \\
\text { на ресурси } \\
\text { • Нов бизнес венчър- } \\
\text { управление на новата дейност }\end{array}$ \\
\hline $\begin{array}{c}\text { Специфики на } \\
\text { управлението на } \\
\text { човешките } \\
\text { ресурси }\end{array}$ & $\begin{array}{l}\text { - Компетентности на } \\
\text { специалистите, необходими от } \\
\text { гледна точка на свързаните със } \\
\text { знанието процеси } \\
\text { - Стимули за обмен на знание } \\
\text { - Обучение и развитие на } \\
\text { кадрите } \\
\text { - Планиране на } \\
\text { приемствеността }\end{array}$ & $\begin{array}{l}\text { • } \text { Развитие на } \\
\text { предприемаческите умения на } \\
\text { специалистите } \\
\text { • Стимули за предприемане } \\
\text { на стъпки, които водят до } \\
\text { иновации } \\
\text { - Осигуряване на свобода на } \\
\text { вътрешния предприемач за } \\
\text { разработване на проект за нов } \\
\text { бизнес и неговата реализация } \\
\text { • Осигуряване на свобода на } \\
\text { специалистите за избор на } \\
\text { начин на изпълнение на } \\
\text { работните задачи }\end{array}$ \\
\hline $\begin{array}{c}\text { Роля на } \\
\text { потребителите }\end{array}$ & $\begin{array}{l}\text { • Привличане на знание от } \\
\text { потребителите } \\
\text { • Водещи потребители и } \\
\text { потребителски общности: } \\
\text { проектиране на свързаните със } \\
\text { знанието процеси } \\
\end{array}$ & $\begin{array}{l}\text { • Предприемачески } \\
\text { инициативи и проекти от } \\
\text { потребителите: анализ на } \\
\text { възможностите, стимули, } \\
\text { процеси, предизвикателства за } \\
\text { управленската система }\end{array}$ \\
\hline Метрики & $\begin{array}{l}\text { - Специалисти: образование, } \\
\text { опит, компетентности } \\
\text { - Вътрешна структура на } \\
\text { знание: патенти, стратегически } \\
\text { и оперативно документи, } \\
\text { процедури, информационни } \\
\text { системи } \\
\text { - Външна структура на } \\
\text { знание: знание от различните } \\
\text { заинтересовани страни } \\
\end{array}$ & $\begin{array}{l}\text { • } \text { Иновативност на продукти, } \\
\text { процеси и бизнес модели } \\
\text { • Автономност } \\
\text { - Проактивност } \\
\text { - Поемане на риск } \\
\text { - Поведение спрямо } \\
\text { конкурентите }\end{array}$ \\
\hline $\begin{array}{c}\text { Организационна } \\
\text { култура }\end{array}$ & $\begin{array}{l}\text { - Споделяне на информация и } \\
\text { знание } \\
\text { - Доверие } \\
\text { - Обучение и развитие }\end{array}$ & $\begin{array}{l}\text { • } \text { Доверие } \\
\text { • Подкрепа на иновациите } \\
\text { • Обучение и развитие } \\
\text { • Неуспехът- източник на } \\
\text { благоприятна възможност }\end{array}$ \\
\hline
\end{tabular}

Източник: Таблицата е разработена от автора

Интерпретацията на теоретичните и емпиричните изследвания по проблематиката позволява да откроим следните области на релащия между управление на знанието и предприемаческа активност:

(1) Стратегия по отношение на знанието- благоприятна възможност за иновации и предприемачество. В този аспект стратегията по отношение на знанието следва да допринася 
както за систематичното и планираното търсене на информация, така и да отчита обстоятелството, че откриването на предприемачески възможности е свързано с изненадата, с неочакваността и със субективното възприятие от страна на предприемача.

(2) Стратегия по отношение на знанието - иновации. Теоретичните постановки препоръчват приложение на два стратегически подхода за управление на знанието: подход на кодирането и подход на персонализацията. Подходът на кодиране се насочва към преобразуване на знанието във форма, подходяща за съхранение в бази знание. Адресира се явното знание, както и преврьщането на скритото знание в явно посредством процес на отчуждаване. Кодирането допринася за ефективно многократно използване на съхраненото знание. В основата на подхода на персонализация е неявното знание и неговият обмен чрез диалог между специалистите от един екип, общност или мрежа. Емпирични изследвания доказват положителната връзка и на двата стратегически подхода с капацитета за създаване на иновации, както и с резултатите от дейността на организацията. Проучвания свидетелстват за въздействие на стратегията за кодиране върху усъвършенстванията и съществените подобрения на продуктите и услугите, получени в резултат нови комбинации от съществуващо знание. Значим е ефекта на стратегията за персонализация върху създаването на нови продукти и услуги (Foray, D., 2006, Lypez- Nicolaz, C., Melono- Cerdan, Е., 2010). В този процес значение оказва съчетаването ѝ с подходящи инструменти и техники за креативност.

(3) Проектиране на свързани със знанието процеси, които позволяват формиране на самоорганизиращи се екипи за разработване на иновации.

(4) Документиране на резултатите от предприемаческите проекти.

(5) Анализ на връзката „свързани със знанието процеси- предприемачески процеси“ и използване на резултатите от анализа за усъвършенстване на свързаните със знанието процеси с оглед насьрчаване на предприемаческата активност на организацията.

(6) Акцент върху организационното учене като процес, целящ от една страна усъвършенстване на свързаните със знанието процеси, а от друга страна вписване на резултатите и опита от реализирани предприемачески проекти, в базата знание на организацията.

(7) Оценка на предприемаческите компетентности на кадрите и приложение на подходи за тяхното развитие.

(8) Проектиране на свързаните със знанието процеси за реализиране на предприемачески проекти от страна на водещите потребители.

(9) Иновации и потребителски общности: проектиране на свързаните със знанието процеси.

(10) Разработване на метрики за оценка от една страна на интелектуалния капитал на организацията, а от друга страна на предприемаческото поведение на компанията. Приложение на методи за измерване.

(11) Разглеждане на организационната култура като трансмитер на неявно знание и анализ на нейното въздействие върху предприемаческата активност.

(12) Разглеждане на неуспеха от реализирани предприемачески проекти и инициативи като опит- обект на систематично документиране и изучаване.

\section{Заключение}

Проведеното изследване дава основание за следните изводи: (1) епистемологичният подход очертава плодотворна перспектива за проучване на предприемаческата активност, 
която има своето теоретично основание и различни аспекти на съвременно приложение. (2) Управлението на знанието и предприемаческата активност са различни, но взаимно свързани концепции, като могат да се дефинират области на релация по компоненти: стратегии, организационни форми, процеси, специфики на управлението на човешките ресурси, роля на водещите потребители и потребителските общности, метрики, организационна култура.

В практико- приложен план проучването позволява формулиране на препоръки в направленията: (1) разработване на стратегия и система за управление на знанието с фокус върху благоприятните възможности за иновации; (2) акцент върху връзката “процеси, свързани със знанието - предприемачески процес“; (3) развитие на предприемачески компетентности на кадрите; (4) разглеждане на организационната култура като трансмитер на неявно знание и ключов фактор за предприемаческа активност. Ангажиментьт на компанията в откроените посоки допринася за формиране на предприемаческа компетентност на организацията и за устойчивост на конкурентното предимство.

\section{References}

1. Mises, L.(2008) Profit and Lose. Auburn, Alabama:Ludwig von Mises Institute

2. Koeva, S. (2002) Pazarat kato spontanen red. Prinosat na F.A. Hayek. Varna: STENO

3. Kirzner, I. (1997) Entrepreneurial Discovery and the Competitive Market Process: An Austrian Approach. Journal of Economic Literature, XXXV, 60-85

4. Drakar, P. (2002) Inovatsii i predpriemachestvo. Sofia: Klasika i stil

5. Koev, Y. (2006) Balgarskoto predpriemachestvo. Protsesni harakteristiki i epistemologichen analiz. Varna: E- LITERA

6. Di Muro, P. and Turner, J.R. (2018) Entrepreneurial opportunity pursuit through business model transformation: a project perspective, International Journal of Project Management, 37 (7), pp. 968-979

7. Pinchot, G. (1985) Intrapreneuring. Why you don't have to Leave Corporation to become Entrepreneur. New York: Harper\&Row Publishers

8. Guth, W and Ginsberg, A (1990). Guest editors' introduction: Corporate entrepreneurship. Strategic Management Journal, 11, pp.5-15

9. Miller, D. (1983) The correlates of entrepreneurship in three types of firms. Management Science, 29 (7) pp.770-791

10. Covin, J. and Slevin, D. (1991) A conceptual model of entrepreneurship as firm behavior. Entrepreneurship Theory and Practice. 1, pp. 7-26

11. Lumkin, G.T. and Dess, G. (1996). Clarifying the entrepreneurial orientation construct and linking it to performance. Academy of management review, 21, pp. 135 - 172

12. Covin, J. and Wales, W. (2019) Crafting high-impact entrepreneurial orientation research: Some suggested guidelines. Entrepreneurship Theory and Practice, 43 (1), pp. 3-18.

13. Nonaka, I. A (1994) Dynamic Theory of Organizational Knowledge Creation. Organization Science, 5 (1), pp.14-37

14. Alavi, M. and Leidner, D. (1999) Knowledge Management and Knowledge Management Systems: Conceptual Foundations and Research Issues. Fountainebleau: INSEAD Working Paper Series

15. Dalkir, K. (2011) Knowledge management in Theory and Practice. 2nd Ed. Cambridge, Massachusetts:The MIT Press

16. Martins, W.V.B., Rampasso, I.S., Anholon, R., Quelhas, O.L.G. and Filho, W.L. (2019), Knowledge management in the context of sustainability: Literature review and opportunities for 
future research, Journal of Cleaner Production, 229, pp. 489-500

17. Leiponen, A. Managing Knowledge for Innovation: The Case of Business- to Business Services. The Journal of Product Innovation Management, 23; 2006, p. 238-258

18. Inkinen, H. T, Kianto, A. and Vanhala, M. (2015) Knowledge management practices and innovation performance in Finland. Baltic Journal of Management, 10 (4), pp. 432-455

19. Pinchot, G. and Pinchot, E. (1996) The intelligent organization: engaging the talent and initiative of everyone in the workplace. San Francisco: Berrett-Koehler Publishers

20. Michael, S., D. Storey and Thomas, H. (2002) Discovery and Coordination in Strategic Management and Entrepreneurship. In Hitt M., D. Ireland, M. Camp, D. Sextion. Strategic Entrepreneurship. Creating a new Mindset. Oxford: Blackwell Publishing, pp.45-61

21. Antoncic, B. and Hisrich, R. (2003). Clarifying the intrapreneurship concept. Journal of Small Business and Enterprise Development, 10 (1), pp. 7-24

22. Kazanjan, R., Drazin, R. and Glynn, M.A. (2002) Implementing Strategies for Corporate Entrepreneurship: A knowledge - Based Perspective. In Hitt M., D. Ireland, M. Camp, D. Sextion. Strategic Entrepreneurship. Creating a new Mindset. Oxford: Blackwell Publishing, pp.173-192

23. Alshanty, A. M. and Emeagwali, O. L. (2019) Market-sensing capability, knowledge creation and innovation: The moderating role of entrepreneurial-orientation, Journal for Innovation \&Knowledge, 4 (3), pp.171-178

24. Foray, D. (2006) Economics of Knowledge. Cambrige: MIT Press

25. Lypez- Nicolaz, C. and Melono- Cerdan, E. (2010) Strategic knowledge management, innovation and performance. International Journal of Information Management, 31, pp.502-509 